\title{
Unutulan Mesafe, Hayvan-Oluş ve Sanat
}

Dr. Öğr. Üyesi. Rahman Işık SARIALIOĞLU

Mardin Artuklu Üniversitesi

GSF, Resim Bölümü

rahmansaral@gmail.com

ORCID: 0000-0002-2015-3341

\begin{abstract}
Öz
Bałı metafiziği geleneği insanı, doğa ve mahlûkat ile arasındaki mesafe üzerinden kurgular. Düşünen insan bir anlamda yüce yetilerini bu mesafede yaratır. Doğa ile insan arasındaki mesafenin kapanma korkusu, modern uygarlığı yaratan bilinçtir. Sanat için ise uygarlığı yaratan bu mesafe; bir tedirginlik ve korku alanı değil, onun ontolojisinin olmazsa olmazı, unutulmuş, sessiz bir varoluş alanının evidir. Sanat; modern insanın uzaklaşmak istediği doğanın sessiz ve kapalı dünyasına sızarak, insanı mümkün olmayan bir bütünleşmenin arzusuyla tanıştırır. Bu unutulmuş arzu sayesinde Sanat, Modern Aklın aksine, ilkel olanın bakışını her daim kendinde saklı tutar ve uygarlık karşıtı bakışı içselleştirir. Hayvanın ve mahlûkatın kapalı dünyasına sızmaya çalışan Sanat, uygarlığın kapattığı o mesafede bir "açıklık" yaratır.
\end{abstract}

Anahtar Kelimeler: Hayvan, Mahlûkat, Doğa, Illkellik, Mesafe, Bakış 


\title{
Forgotten Distance, Being-Animal and Art
}

\begin{abstract}
The western metaphysics tradition fictionalizes the man on the distance between nature and the living creatures. Thinking man creates his supreme abilities in this distinction. The fear derives from the idea of closing down the distance between nature and man is the origin of consciousness that creates modern civilization. For art, this distance that creates civilization is not an area of anxiety and fear, but the home of a forgotten, silent realm of existence, the sine qua non of its ontology. Art; through infiltrating into the silent and closed world of nature, which modern man wants to get away from, introduces man to the desire of an impossible integration. Thanks to this forgotten desire, Art, unlike the Modern Reason, always keeps the view of the primitive in itself and internalizes the anti-civilization view. Art, trying to infiltrate into the closed world of animals and creatures, composes an "openness" in the distance that the civilization covers.
\end{abstract}

Keywords: Animal, Creatures, Nature, Primitivity, Distance, View 


\section{arts}

\section{Gíiş̧}

"Ama yine de doğalarından deneysel bilgi edinmek için hayvanlara gereksinim duyuyorlardı."

Aquino'lu Tommaso

"Hayvanlık, dolaysızlık veya içkinliktir" diyor Bataille ve ekliyor; "Aslan, hareket eden sularda, daha küçük dalgaların üzerine devrilen büyük bir dalgadır." (Bataille, 2013) Hayvanın bir başka hayvanı yemesinin bir tahakküm ilişkisi değil, bedenden bir başka bedene geçiş, bir devamllık olduğunu ifade ediyor Bataille. "Bize, içinden çıktı̆ı̆ımı bu hayvan yaşamından daha kapalı bir şey yoktur. Bizim düşünce biçimimize, sessiz kâinatın bağrındaki yeryüzünden daha yabancı bir şey yoktur." (Bataille, 2013) Düşünen insanın varoluşu, bu hayvansı devamllığa yabancılaşmış bir varoluş hâli. Peki, hayvan yaşamının kapalı varoluş alanına insanın sızabilmesi mümkün müdür? Ya da bu kapalı varoluş alanına açık, dolaysız bir bilgi türünün imkânsızlığı sayesinde mi Sanat, sessiz dilini yaratmıştır? Bütün bu soruların kesin cevapları olmasa da, Sanatın; Akıl ile insana kapalı olan hayvan yaşamının -Bataille'in deyişiyle sessiz kâinatın- arasında bir varoluş̧a şekillendiğini hissedebilmek mümkündür. Sanat, mümkün olmayan bir dolaysızlıktan ve içkinlikten kaynaklanan bir haz formudur. Bizim düşünce biçimimiz ve Sanatın madde ile düşünebilme yetisi arasındaki fark; soyutlayan, kavramsallaştıran metafizik düşünce ile maddeye içkinleşmeye çalışan bir arzunun ayrımından doğar. İnsan, metafizik düşünme şeklinden farklı olarak, sanat eylemiyle birlikte varolanı yine bir madde aracılığıyla hissetmeye ve düşünmeye çalışır. Nesnenin üzerinde bir hayaleł gibi gezinen düşünce maddeleştiğinde, insan yabancısı olduğu bir doğanın alanına geçiş yapmış olur. Bir hayvanın kendi bedeninden bir başka bedene geçişi gibi, insan da bilinmesi mümkün olmayan bir öteki doğaya geçişi madde aracılığıyla arzulayarak, hayvanın deneyimine hem uzak hem de yakın bir deneyim yaşar. Uzaklığı özdeşleyimin imkânsılığından dolayıdır. Dünyanın düşünce biçimimize olan yabanclığı, tamamlanması mümkün olmayan bir içkinliğin yaratıı̆ı bir "yalan varlığın" -Sanat Yapıtı- deneyimi ile aşıır. Alice'in tavşan deliğini anımsatan estetik büyünün olasılığı; insan zihninin ötesinde değil, hayvan ile insan arasındaki mesafede saklıdır. Daha doğrusu büyü, bu mesafeyi unutabilmeye çalısan insanın yaşadığı imkânsızlıktan doğan arzudur. Fakat ortaya çıkan yapıtın bir unutuş formu olduğunu söyleyebilmek mümkün. Bu yüzden büyünün devrimci doğası sanatçıdan çok sanat 


\title{
$\operatorname{arts}=$
}

yapıtında gizlidir.

Schiller'in ve diğer romantiklerin, uygarlığın hastalığı ile baskıcı mantığın karşısına duyumsallığı ve aşağı yetileri koymaları elbette bir rastlantı değildi. Bu "unutuş formunu" (Sanat) yaratabilmek için insanın kaybettiği aşağı yetilerinin ilkel dünyasını hatırlaması gerekliydi. İlkel yetilerimizi hatırlamak veya yüceltmek; uygar insanın mahlûkatile arasına koyduğu mesafenin tam anlamıyla unutuımasını mümkün kılmasa da, bu unutma sancısı sayesinde bir karşı-varoluş yaratmak mümkündür.

\begin{abstract}
"Schiller, uygarlığın hastalığını, insanın iki temel itisi (duyumsal iti ile form itisi) arasındaki çatışkı olarak, daha doğrusu bu çatışkının bozucu çözümü olarak, yani, mantığın duyumsallık üzerinde baskıcı bir istibdat kurması olarak teşhiş etmiştir. Buna bağlı olarak, karşıt itilerin uzmanlaştıııması, bu istibdatın kaldırımaşını, yani, duyumsallığın haklarının geri verilmesini gerektirecektir. Özgürlüğün, mantık yerine, duyumsallığın kurtuluşunda ve yüce yetilerin aşağılık yetiler lehine sınırlandırılmasında aranması gerekecektir." (Marcuse, 1968, s.217-218)
\end{abstract}

"Aşağı yetiler" sanatın oluş sürecinde kilit kavramlardan biridir. Sanatın sürükleyici ve yaratıcı gücünün kökeni bu yetilerin özlemi ile ilgilidir. Elbette, insanhayvan ayrımının ortadan kalktığı bir geleceği düşlemek mümkün değil. Böylesi bir bütünleşmenin insanı verili olan dünyaya kapatacağı gayet açıktır. Tuhaf gelebilir fakat kapitalist uygarlık, tam da Akıl merkezciliği ile korktuğu hayvan-oluş durumunu tersten yaratmıştır. Ne demektir bu? İnsan, aşağı yetilerini yüce yetileri adına terk ederek ve Aklı, insan-oluşun merkezine yerleştirerek yüce yetilerinin sınırlı doğasını yaratmış oldu. Bir anlamda insan; övündüğü, hayvan ile kendisi arasındaki mesafenin ideolojisinde kısılıp kaldı.

\footnotetext{
"Aydınlanma sayesinde özgürleştirilen insanlar sonunda, doğadaki her şeyi yinelenebilir kılan soyutlamanın ve bu soyutlamanın hazılladığı endüstrinin düzleştirip eşitleyen egemenliği altında, Hegel'in Aydınlanmanın bir sonucu olarak nitelendirdiği düzenli birlikler haline geldiler." (Adorno, Horkheimer, 2010 s.31)
}

Batı felsefesi, düşünen insan ile mahlûkat arasındaki fark ve doğa karşıtlığı üzerinden kendi geleneğini kurgular. İktidar, bu mesafenin yarattığı şiddetin izlerini içselleştiren bir olgudur aynı zamanda. İnsanın doğa ya da hayvanla bütünleşme korkusu ve bu mesafenin yarattığı üstün bilinci, korku nesnesini (Doğa, Mahlûkat, Hayvan) egemeni olduğu kendi nesnesine dönüştürmüştür. Kapitalizm; bir anlamda insanın doğa ile olan mesafesini, doğayı sürekli sömürerek sabit tutma eylemidir. 


\title{
arts
}

Soyutlanan ve düzleşen dünya, bu mesafenin yarattığı bir dünya olabilir mi?

\begin{abstract}
"Avrupa tarihinde insan ideası kendisini, insan ile hayvan arasındaki farkta ifade eder. Hayvanın akıldan yoksun oluşu insanın saygınlığına kanıt olarak gösterilir... Halk masallarında insanların ceza olarak bir hayvana dönüşümü yinelenip durur. Insanın bir hayvan bedenine hapsedilmiş olması bir lanet anlamına gelir. Çocuklar ve halklar bu türden başkalaşımları dolaysız biçimde tanıyıp bilirler. En eski kültürlerdeki ruh göçüne ilişkin inanç bile hayvan biçimini bir ceza ve işkence sayardı. Hayvanın bakışındaki suskun vahşet, insanların bu türden bir dönüşümden duydukları dehşetin aynısını imler. Her hayvan eski çağlarda meydana gelmiş ve derin bir etki bırakmış bir felaketi hatırlatır. Masallar insanın sezdiklerini dillendirir. Prensin aklı yerinde olduğu için zamanı geldiğinde derdini dile getirip perinin büyüyü bozmasını sağlayabilir; akıldan yoksun oluşu hayvanı sonsuza dek o biçimin içine hapseder. Bundan kurtulmanın tek yolu, geçmişi dolayısıyla hayvanla bir olan insanın büyüyü bozan sözü keşfedip, bu söz sayesinde zamanın sonunda sonsuzluğun taştan kalbini yumuşatmasıdır." (Adorno, Horkheimer, 2010 s. 327, 329,330)
\end{abstract}

Hayvanın bakışındaki suskun vahşetten doğan mesafenin bilinci Aydınlanmış Öznenin yaratılmasında önemli bir unsurdur. Peki, Sanat böylesi bir insan ve hayvan oluş mesafesinde kendini hangi konuma yerleştirir? Sanatın insan-hayvan mesafesini bozan söz ile yetinmemesi, onu insan-hayvan ayrımının sınırlarında gezinen ve bu aralıkta varoluş olanaklarını arayan bir deneyime dönüştürür. Elbette Sanat, sadece insan-hayvan varoluşu aralığında gezinen bir deneyim değildir. İnsanı salt söz ile tanımlamayan doğası sayesinde Sanat; aşağı yetileri, insanı insan yapan yüce yetilerle eşitleyerek, sözü edilen mesafede bir karşı büyü arayışına dönüşür. Hayvan oluş bir içkinlik ve dolaysızlıksa eğer, Sanatın bu oluş ile ilişkisi; mümkün olmayan bir içkinliğin özleminde gizlidir. Sanatın yaratıcı kökeni "dil" öncesi zamanlara dayanan oyun ile ilişkiliydi. Doğa ile birlikte kurgulanan bu oyun sayesinde, insanın bir karşı alan yaratma arzusu içinde olduğunu söyleyebilmek mümkündür. Fakat dünya ile içkinleşebilmenin imkânsızlığı sayesinde Sanat; verili dünyanın dışında, kendine özgü bir uzama dönüşür. İnsanoğlunun ilk dönemlerine ait mağara resimleri, hayatın içinde olduğu kadar dışındaydı da. Sanatın eş zamanlı bir şekilde dünyaya ait ve yabancı ontolojisi (oyun) insanı, sessiz kâinatın yabancılığına yaklaştıran en önemli eylemdi. (Sanat, din ile eş zamanlı bir eylemdi.)

Dünya ile insan arasındaki boşluk, modern insanın düşünce biçimine yabancı bir alan. Bu boşluk hayvan yaşamının ve yeryüzünün korkutucu sessizliğini barındırır. Düşünce biçimimize kapalı olan yoğun oluş halleri gizlidir bu boşlukta. Boşluğa, bir başka deyişle hayvana ve doğaya bakışın ideolojisi, düşünce biçimimiz ve kadim sanat eyleminin arasındaki farkı oluşturur. Bakışın ideolojisi, kendine özgü ve yabancısı olduğumuz oluşlar ile aramıdaki farktan beslenir. Daha önce de belirtildiği gibi Batı 


\section{$\operatorname{arts}=$}

metafiziği kendini bu ontolojik fark üzerine kurgulamış ve dünyanın merkezine insanı ve onun üst yetilerini yerleştirmiştir. Sanat ise kendini dil ve üst yetilerle sınırlamayan doğası sayesinde, yabancısı olduğumuz mahlûkat ile aramızdaki mesafenin gizemli doğasına girmeyi arzulayan eylemdir. Kendisini insanın Aydınlanma sonrası tamamen unuttuğu ilkel dürtülerinin oluşlarına açar. Sanat bir nevi, ilkel oluşların uygarlıkla çatışmasıdır! İnsana kapalı olan mahlûkatın yaşamını, mümkün olmayan bir özdeşleyimin yarattığı özel bir alan olan Sanat yapıtında sezebilmek mümkündür. Sanat yapıtının yaratığı alan nasıl böylesi bir seziyi mümkün kılabilir? Sanatın söz ve söylem ile arasındaki sorunsallığı, böylesi bir sezinin olanaklarını kendinde barındıran bir ontoloji yaratır. Sanat, Aklın ve söylemlerinin kendi içine kapattığı dünyayı, doğa ile aramızdaki mesafeyi hatırlayarak yeniden açar. Sanat yapıtında görünür olan; unutulan dünyadır. Kendisini unuttuğumuz hayvansı-ilkel dürtülerimiz üzerinden kurgulayan Sanat; zihinsel tasarımın kurguladığı mevcut dünyayı terk etme çabasının bir sonucudur. Elbette kimilerine abartılı gelebilecek olan bu cümleler, zihinsel ve akli olanın Sanatın sınırları dışında kaldığı izlenimini verebilir. Elbette zihinsel kurgu Sanat eserinin olmazsa olmazıdır. Söylenilmek istenilen; zihinsel kurgunun nasıllığı ve ilkel dürtülerimiz üzerindeki egemenliği ile ilgilidir. Sanat, sahip olduğumuz aklın yarattığı kurgu ve unutulan ilkel dürtülerimizin eş zamanlılıkla birbirinde eridiği bir denge dünyasıdır. Bir anlamda, metafizik ve toprak arasındaki dengedir. Verili dünya da sahip olamayacağımı bu dengeyi, Sanatın yabancı doğasında yaratmak mümkündür ancak. Peki, bu denge nasıl yaratıır? Böylesi bir ontolojiyi derinlemesine incelemek bu kısa makalede mümkün olmasa da Aklın ve Sözün egemenliğinin yarattığı verili dünyaya karşıt ontolojiye değinmek, okuyucuya farklı bir bakış açısı kazandırabilir. Söz ve anlam ile yetinmeyerek mahlûkata yaklaşan Sanat arzusu, uygarlık ile arasındaki mesafeyi açar. Bir bütün olarak insan, ancak bu geçmişe dönük aşkın boşlukta varolabilir. 


\section{Köpeğin Uluması ve Uzayan Bakış}

"O varlıkla var olanlar arasındaki farkın ötesine geçmiş bir varolandır, bir gerçektir."

Giorgio Agamben

Tan vakti uzun uzun uluyan bir köpek! Uzayda uzayarak kaybolan bu ses bizim dünyamıza tamamen kapalıdır. Tan vaktinin zifiri karanlığında kendi özel, kapalı dünyasına açılan bu sessiz sesin Sanatın ontolojisiyle nasıl bir ilişkisi olabilir? Hayvanların asla bilemeyeceğimiz varoluşu ve bu varoluşun doğa ve evrenle sessiz ilişkisi, Sanatın sessiz ve derin doğasına benzer bir ontoloji gibi. Bu benzerlik doğa ve evrenin bir parçası olduğumuz bilgisinden mi kaynaklanıyor? Sanat eylemi; tıpkı köpeğin uluduğu âna benzer bir dolayımsızlığın ve bütünlük hasretinin, bir zihindışı hatırlanışı olabilir mi? Sanat, doğadan bizi ayıran Aklın yerine, aklı da içeren bir hücresel düşünme biçimi. Sanılanın aksine Sanat; doğayla arasına mesafe koyan kadim uygar insanın bir kültür eylemi değildir sadece. $\bigcirc$, aynı zamanda bu mesafenin yarattığısancıdan doğan, kültür- dışı öğeleri de kendinde barındıran ilkel dürtülerimizin arzusudur. Söz, kopmuş olduğumuz dünya ile olan mesafeyi her zaman sabit tutan kavramlar dünyasına ait bir büyü. Sanat ise söz ile ilişkili olsa da onunla yetinmeyen ve sözün yaratmış olduğu sancıyı imgeler ile yatıştırmayı arzulayan bir karşı büyüdür. İmgeler ve köpeğin uluması, bilinemeyen bir taşkın sarhoşlukta birbirlerine yaklaşırlar. Varlık ve var olanlar arasındaki farkın ötesine geçerek ölümün kıyısına yaklaşırlar. (Agamben, 2009) Hayvanların insanlardan çok daha yoğun yeryüzüne yapışı doğaları ve bu doğadan kaynaklanan oluş olanaklarının sınırlıl̆ı ölüm çığlığının "duyulan" kısmını azaltan bir unsurdur. Hayvanın çığlığı sözü içermediği için doğaya içkindir. İnsan ise kavramlar yaratan doğası sayesinde dünya ile çok daha derin bir ayrım üzerinden varoluşunu kurgular. İnsanın gerçeğe yaklaştığı o taşkın ve tekinsiz ölüm kıyısı, hissettiği mesafenin derinliği yüzünden zengin imgelerin hazzına dönüşür. Sanat, bir ölüm hazzıdır. Bir başka deyişle hayvanın kendi sınırlı dünyasına kapanması gibi, ölümün yaşamdaki derin kopuşu kendi içinde kapatmasıdır. Yaşam ve ölüm eşit düzleme yerleşerek, insana ait eylem sonsuz eyleme dönüşür.

Sözü edilen mesafeyi insan olmanın şartı olarak gören uygarlığın aksine, sanat eylemi bu mesafeyi hissettiği anda eyleme geçer. Ve dolan boşluk (Sanat Yapıtı) 


\section{arts}

verili dünyanın karşıtı olarak zengin imgelerle açığa çıkar. Bu zenginlik daha önce de belirtildiği gibi bilincin yarattığı ayrımın çok derin olmasından kaynaklanır. Marcuse'un deyimiyle dünya aslında sanat yapıtında göründüğü gibidir. (Marcuse, 1997 s. 11) Çünkü Sanatın kurgusal doğası insanın asla geri gelemeyecek, unutulmuş varoluşuna dayanır. Hayvan doğamızı unuttuğumuz gerçeğine ilişkindir bu varoluş. Yaşamı ve ölümü eşit düzleme yerleştiren; bu unutulmuş varoluşu hatırlama arzumuzdur.

Sanat yapıtı noktasız bir cümledir. Ama tuhaftır ki noktası olmayan bir anlatıya cümle denmesi mümkün değildir. Sürekli uzayan bir anlatıdır o. Anlatı dışı bir anlatı. Köpeğin uzayda uzayan ulumasına benzeyen, ölümü hissettiren sessiz bir anlatıdır. İmgenin dünyada açtığı boşlukta ve ölüme yakın yaşamın taşkınlığında bakış; sürekli uzayan bir nitelik kazanır. İmkânsız bir dolaysızlığı arzulayan bakış, şeyler arasında sonsuz devamlılığı yaratır ve bu devamlılık sayesinde unutmuş olduğumuz hayvan doğamıza yaklaşır. Sanat imgesi, noktasız anlatısıyla mahlûkat ile arasındaki mesafede kendini kurgulayan Aklın metafiziği yerine daha doğrudan, derin bir algı yaratır. Ölümün yaşama kapanması ve yaşamın unutulan dünyaya tekrar sızabilmesi tam da bu doğrudan bakış ile ilişkilidir. Bir sanat yapıtına bakıldığında, yaratılmış imgenin kendini sürekli sonsuz bakışa açan noktasız varoluşu ile karşılaşırız. Varlıkta boşluk yaratan, varlığın kuyusunu kazan bir varoluştur bu. İnsan, kendine verili olan mevcut dünyayı ve yüce yetilerimizin yarattığı ideolojik anlamları mümkün olabildiğince -ki insan ideolojik bir varlıktır ve bu dolayımdan tamamen sıyrılması mümkün değildir- teğet geçen bu bakış sayesinde mahlûkata yaklaşır. Kendine ait bir doğası olan "ben" ile "ben"in dışında varolan doğa arasındaki geçişler, bir başka deyişle bir düşünen doğadan kendinde bir doğaya sızma eylemi ve özdeşleyimin imkânsızlığı, güzelliği yaratan kıvılcımdır! Güzel, yüce yetilerimizin mimarı olan Akıl tarafından kurgulanamaz. O olsa olsa, Aklın ve onun aygıtlarının sızamadığı, unutmuş olduğumuz doğamızın arzulandığı bir boşlukta filizlenebilir ancak. Sanatın ontolojisindeki sonsuz hazzın kökeninde, doğaya ait olduğumuzu bize hatırlatan ilkel bir dürtü gizli değil midir? Ya da varlıkta uzayan, bir sonu olmayan "ben"in bakışı (Sanat Yapıtı) sonsuzda doğaya ve ölüme dönüşmez mi? Köpeğin karanlık geceye ulumasının, gecenin kendisi olması gibi! 


\section{$\operatorname{arts}=$}

\section{SONUÇ}

Sanatçının bakışı salt kendine ait bir varoluşu görünür kılmaz. Ressamın bir nesneye (doğaya ya da kendi doğasına) bakışı sonucu oluşan bir imge, salt öznenin bakışından ibaret değildir elbette. Çünkü bakış, yaratma süreci içinde nesnenin kendi doğasının kapalı dünyası tarafından da şekillenir. Bakış yaratıcı olduğu kadar edilgendir de. Nesneye ne kadar şiddet uygulasa da, bakışın bir yanı hep o nesnenin kapalı dünyasına aittir. Yaratmak, insan ve doğa arasına "yüce" bir mesafe koyanların hissettiği gibi nesneler dünyasından kopup, kendi gerçekliğimizin kutsanması mıdır? Yoksa derinlerde bir yerlerde, bir yok alanda hissettiğimiz ilkel dürtülerimizin bizi kayıp olana yönlendirdiği doğanın çağıısı mıdır? Şu soruyu sormamız gerekir. İnsan, yaratma eyleminde nesneden kopma arzusu mu hisseder? Yoksa insan, nesneler dünyasının o yok alanı tarafından çağrılan mıdır? Öyle bir doğadır ki bu hem vardır hem de yoktur. Hem yaşamdır hem de ölüm. Unutulmuş olan mesafe, o unutuşu hissedenler tarafından sessiz bir varlığa dönüştürülür. Kendini evrene; bize kapalı olan o gizemli alana açabilmek için mahlûkatın diline benzer bir dile muhtacızdır. Çünkü hayvan oluşun dili yoktur! O sadece eyler.

"Üç Ayaklı Köpek

Uyandım bir sabah

Sevgiler saygılar sundum kendime.

Ben yürüdüm yol arkamdan geldi

Dönüp bakmadım bile.

Bir ikindi vakti

Üç ayaklı bir köpek

Kesik kesik soluyarak geçti önüme

Gitti bir ağacın gölgesine oturdu

Tek bacağını çekti çenesinin altına. 


\section{arts}

Bir çöp kamyonunun etrafında dolaşırken kaptırmış ayağını. Alçıda unutulan bacak çürüyüp kopmuş. O da çoktan unutmuş acısını.

Kısarak gözlerini dedi ki bana;

-Benim bacağımla ödediğim şeyi

Sen yaşadıkça ödeyeceksin.

$\mathrm{Ne}$ sen bana acl, ne ben sana!

Üç ayaklı köpek ve ben

Birbirinin gözlerine baka baka

Bitirdik bu şiiri." (Sarıalioğlu, 2015 s.72-73)

İnsan yavaş yavaş ve yaşayarak kaybettiği o doğayı duyumsar. Ve Sanat ancak mahlûkatla karşılıklı bakışarak kaybedilen o mesafede varlık kazanabilir!

\section{KAYNAKÇA}

Adorno, T. Horkheimer, M. (2010). Aydınlanmanın Diyalektiği. (Çev. N, Ülner. E, Öztarhan Karadoğan). İstanbul: Kabalcı Yayınevi

Agamben, G. (2009). Açıklık. (Çev. M. M. Çlingiroğlu). İstanbul: Yapı Kredi Yayınları

Bataille, G. (2013, Ağustos). Muamma. E-Skop. https://www.e-skop.com/ skopbulten/pasajlar-muamma/1315. Erişim Tarihi: 01. Eylül. 2019

Marcuse, H. (1968). Aşk ve Uygarlık. (Çev. S. Çağan). İstanbul: May Yayınları. Marcuse, H. (1997). Estetik Boyut. (Çev. A. Yardımlı). İstanbul: İdea Yayınları.

Sarıalioğlu, K. (2015). Temmuz Sağanakları. İstanbul: Komşu Yayınları, Yasakmeyve 